\title{
A Study of the Properties of Electrical Insulation Oils and of the Components of Natural Oils
}

\author{
Milan Spohner \\ Dept. of Physics, Brno University of Technology, Technická 10, 61600 Brno, Czech Republic \\ Corresponding author: xspohn00@stud.feec.vutbr.cz
}

\begin{abstract}
This paper presents a study of the electrical and non-electrical properties of insulating oils. For the correct choice of an electrical insulation oil, it is necessary to know its density, dynamic viscosity, dielectric constant, loss number and conductivity, and the effects of various exposure factors. This paper deals with mathematical and physical principles needed for studying and making correct measurements of the dynamic viscosity, density and electrical properties of insulation oils. Rheological properties were measured using an A\&D SV-10 vibratory viscometer, and analytical balance with density determination kit, which operates on the principle of Archimedes' law. Dielectric properties were measured using a LCR meter Agilent 4980A with connected with the Agilent 16452A test fixture for dielectric liquids.
\end{abstract}

Keywords: conductivity, density, dielectric constant, FAME, insulating oil, lauric acid, loss number, methyl ester, midel, oleic acid, rapeseed oil, stearic acid, transformer oil, vegetable oil, vibratory viscometer, viscosity.

\section{Introduction}

Mineral oil is used as a dielectric in transformers, and also in cables and capacitors. The advantage of mineral oils over other types of oils is their high resistance to aging. A transformer oil must have require low viscosity. For the selection of the oil is also important to consider the construction of the transformer in which will later be filled. The oil is necessary to determine long term stability and whether the oil suitable rheological properties. That can affect the required heat dissipation (cooling), leakage or loss of oil from the transformer. For all types of mineral and non-mineral transformer oils, we need to know in particular the following parameters: dynamic and kinematic viscosity, density, flash point, pour point, breakdown voltage, relative permittivity, loss number, and oxidative stability. The most important parameters of transformer oils include long-term stability of parameters that affect the reliability of the equipment, and especially the costs of operating transformers in distribution systems. Fig. 1 shows the fatty acid content in selected oils.

Natural esters and primarily rapeseed oil were previously considered unsuitable, especially due to the low oxidative stability. For the production of renewable oils are suitable oilseed crops grown commercially in farming. Liquids made from these seeds are composed of triglycerides. Triglyceride is a molecule of glycerol associated with three molecules fatty acids. Unsaturated fatty acids in the liquid exhibit lower oxidative stability and lower dynamic viscosity values [3].

Tab. 1 presents the most frequently used parameters of mineral, synthetic and natural oils. Values are de- fined for pentaerythritol tetraoleate, oleic acid methyl ester (methyl oleate) and synthetic ester (MIDEL $7131)$.

\section{$1.1 \quad$ Rheological properties}

Important rheological properties for oils used in electrical engineering are viscosity and density, which affect the behavior of the liquid in dependence on changes in operating temperature. If these parameters are not within the required tolerances is due to poor lubrication of moving parts and loss or leakage of liquid from the transformer.

Density measurements based on use of the Archimedes principle take into account the gravity and buoyancy force acting on the plunger (calibrated glass weights) with a defined volume $\left(V_{p l}\right)$. In order to calculate the density, it is necessary to know the weight of the plunger calibrated (calibrated glass weight) in air $\left(m_{A}\right)$ and immersed in the liquid $\left(m_{L}\right)$. The density of the liquid can be calculated according to the equation:

$$
\varrho=\frac{m_{A}-m_{L}}{V_{p l}}
$$

where the density $\varrho$ is using the unit $\mathrm{g} \mathrm{cm}^{-3}$ and where it is necessary to know the weight air in the plunger (hanging in the cupboard by simply weighing the influence of air) and its weight after immersion in a liquid. Fig. 2 shows a plunger (calibrated weights) in the measurement of their weighted hanging in the cupboard and immersion in the liquid. 


\begin{tabular}{|c|c|c|c|c|c|c|c|}
\hline Canola oil & 7 & 21 & 11 & & & & 61 \\
\hline Safflower oil & 8 & 14 & & & & & 77 \\
\hline Flaxseed oil & 9 & 16 & & & & 57 & 18 \\
\hline Sunflower oil & 12 & 71 & & & & & 16 \\
\hline Corn oil & 13 & 57 & & & 1 & & 29 \\
\hline Olive oil & 15 & 9 & 1 & & & & 75 \\
\hline Soybean oil & 15 & 54 & & & & 8 & 23 \\
\hline Peanut oil & 19 & 33 & & $*$ & & & 48 \\
\hline Cottonseed oil & 27 & & 54 & & & * & 19 \\
\hline Lard & 43 & & 9 & 1 & & & 47 \\
\hline Palm oil & 51 & & & 10 & * & & 39 \\
\hline Butter & 68 & & & & 31 & & 28 \\
\hline \multirow[t]{3}{*}{ Coconut oil } & 91 & & & & & & 27 \\
\hline & \multicolumn{2}{|c|}{ SATURATED FAT } & POLYUNSATURATED FAT & & & \multicolumn{2}{|c|}{ MONOUNSATURATED FAT } \\
\hline & $\square$ & & $\begin{array}{l}\text { linoleic acid } \\
\text { (an omega-6 fatty acid) }\end{array}$ & & $\begin{array}{l}\text { alpha-linolenic acid } \\
\text { (an omega-3 fatty acid) }\end{array}$ & & $\begin{array}{l}\text { oleic acid } \\
\text { (an omega-9 fatty acid) }\end{array}$ \\
\hline
\end{tabular}

Figure 1: Comparison of the fat content found in natural oils [7].

\begin{tabular}{cccccc}
\hline Oil & $\begin{array}{c}\text { Density } \\
{\left[29^{\circ} \mathrm{C}\right]\left(\mathrm{kg} \mathrm{m}^{-3}\right)}\end{array}$ & $\begin{array}{c}\text { Kinematic viscosity } \\
{\left[27^{\circ} \mathrm{C}\right](\mathrm{cSt})}\end{array}$ & $\begin{array}{c}\text { Flash points } \\
\left({ }^{\circ} \mathrm{C}\right)\end{array}$ & $\begin{array}{c}\text { Pour point } \\
\left({ }^{\circ} \mathrm{C}\right)\end{array}$ & $\begin{array}{c}\text { Dielectric } \\
\text { constant }\end{array}$ \\
\hline PETO & 910 & 128 & 255 & -12 & 3.1 \\
\hline Methyl Oleate & 875 & 9 & 188 & -6 & 3.2 \\
\hline Midel 7131 & 950 & 53 & 233 & -20 & 3.2 \\
\hline
\end{tabular}

Table 1: Parameters of different kinds of oils (mineral acid methyl ester, synthetic oil) [6].

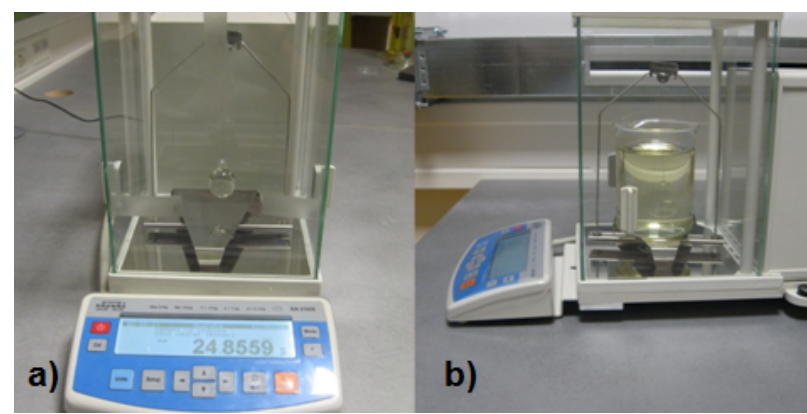

Figure 2: Set for density measurement: a) the plunger weighted in the air, b) specific and calibrated plunger suspended on a hanger and immersed in a liquid for the measurement [5].

\subsection{Dielectric properties}

For the correct selection of electrical insulation liquids, it is necessary to know the following dielectric properties: dielectric constant and loss number. Another relevant parameter is the influence of temperature on changes in the parameters. Oils are tested in laboratory conditions using various accelerated aging tests in order to monitor changes in parameters over time. The changes are mainly influenced by the oxidative stability of the oil.
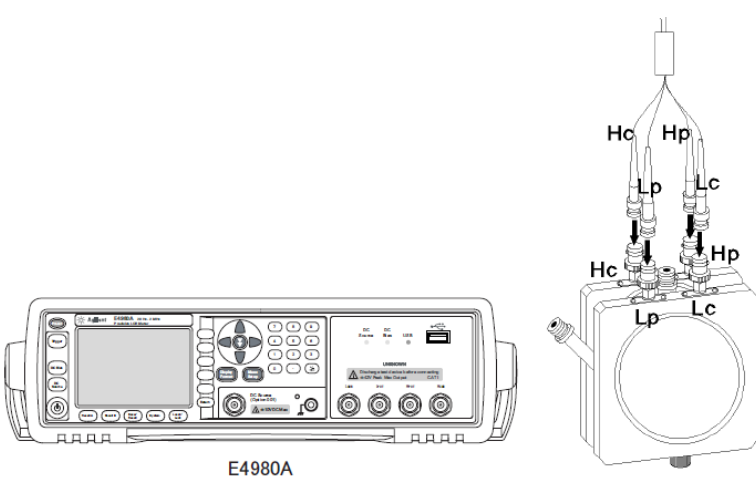

Figure 3: Figure RLCG meter and electrode system for measuring the liquid samples $[1,2]$.

The conductivity of the liquid insulating material is influenced by the concentration of free carriers of electric charge, which may be due to the ionization of neutral molecules, molecular dissociation own liquid and dissociation of molecular masses cause emission of electrons from the cathode in a strong electric field and thermal excitation of electrons. The temperature dependence of the mobility of free carriers of an electric charge causes strong dependence of conductivity on the temperature of the insulating liquid. Technically pure liquids with conductivity in the order of 


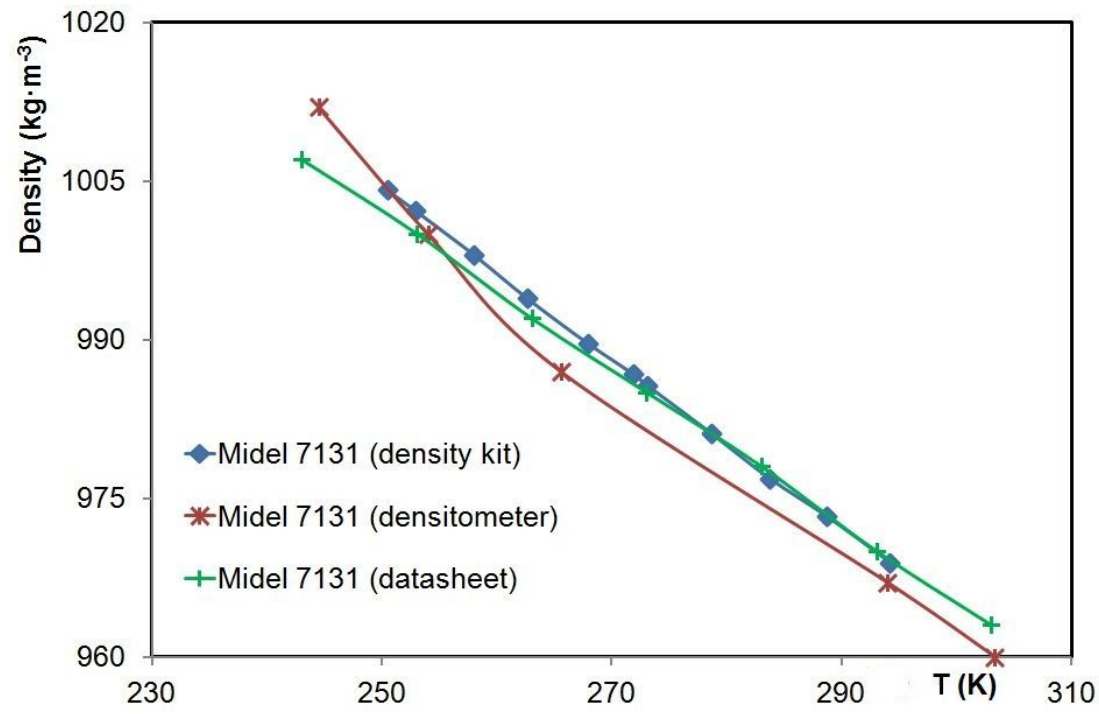

Figure 4: Comparison of the catalog density values for MIDEL 7131 oil, using two measurement methods.

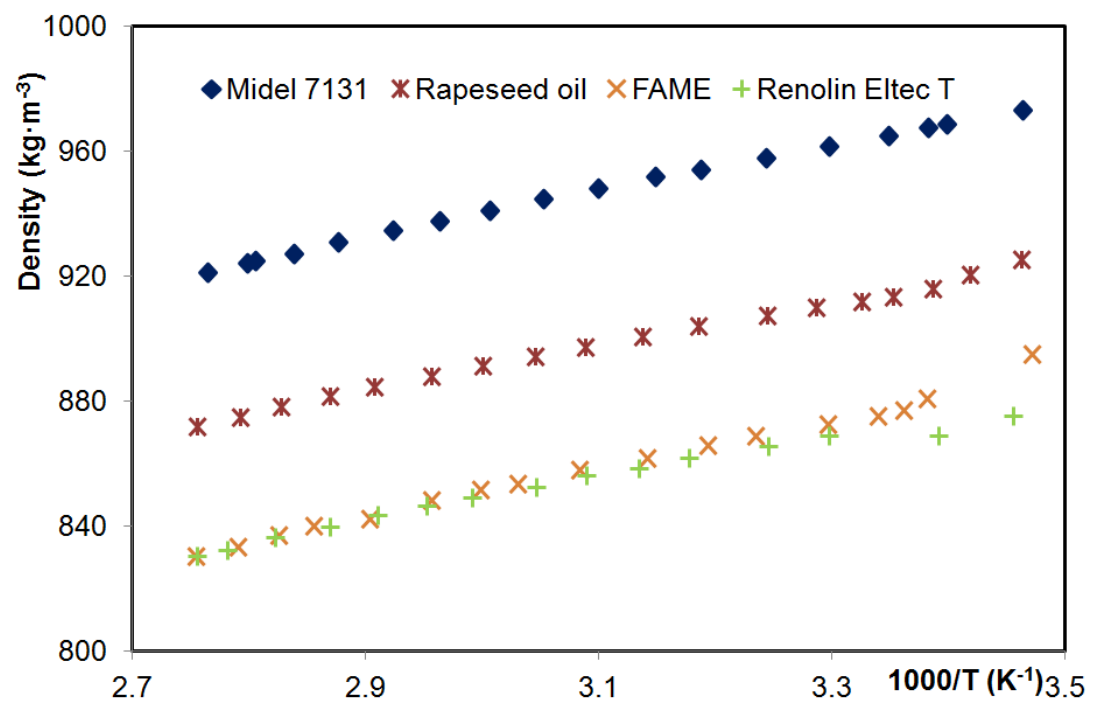

Figure 5: Dependence of density on inverse temperature for various oils.

$10^{-11}$ to $10^{-12} \mathrm{~S} \mathrm{~m}^{-1}$. The mobility of free carriers affects the viscosity, which is a rheological parameter. The relationship between conductivity and dynamic viscosity can be described by Walden's law [4]. Fig. 3 shows the LCR meter and electrode system used for the liquid samples.

\section{Experimental}

\subsection{Rheological properties}

For examining disparities of density mineral, synthetic and natural oils were the following samples: synthetic ester (Midel 7131), natural (rapeseed oil, methyl ester rapeseed oil (FAME)) and one mineral Renolin Eltec T.
The experiment measured density values in dependence on temperature, using two methods. The first method involved measuring the density using a standard glass densimeter, while the second method used the RADWAG analytical balance with density determination kit to determine density according to equation (1). These two methods are compared in Fig. 4 with datasheet value manufacturer of synthetic oil MIDEL 7131. The waveform in Fig. 5 shows the density in dependence on the inverse temperature interval from 270 to $350 \mathrm{~K}$. The lowest values were for mineral oils and methyl ester rapeseed oil.

An A\&D SV-10 vibration viscometer with a maximum range of $10 \mathrm{Pas}$ was used for the dynamic viscosity measurements. To ensure reproducibility, the measurements were performed in the Agilent Vee Pro software automation environment. The values ob- 


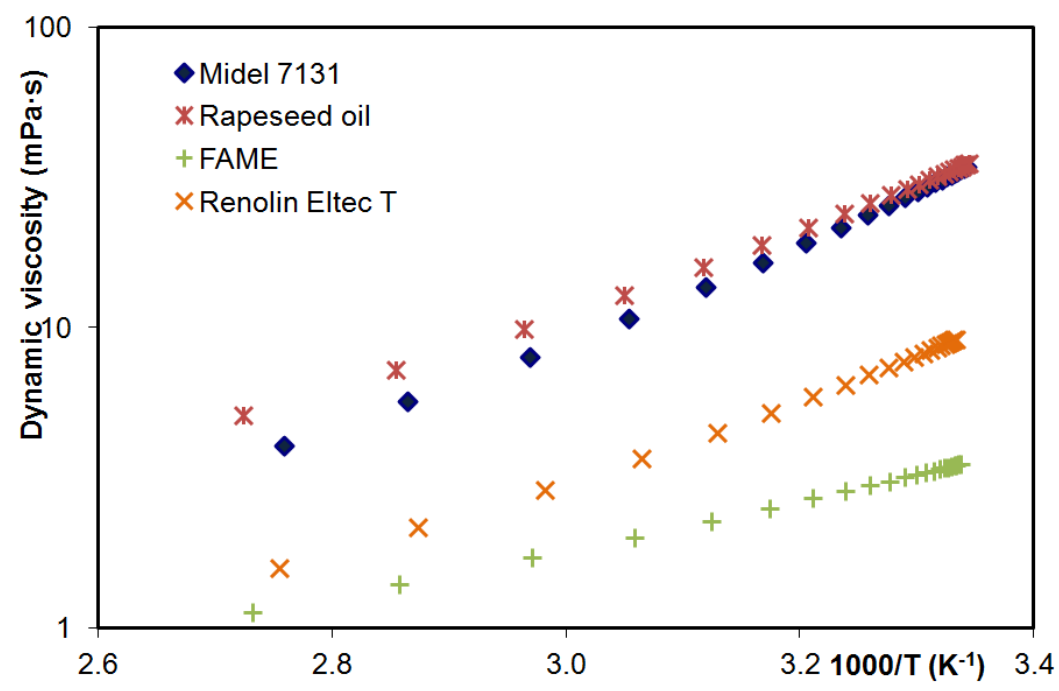

Figure 6: Dependence of viscosity on inverse temperature for various oils.

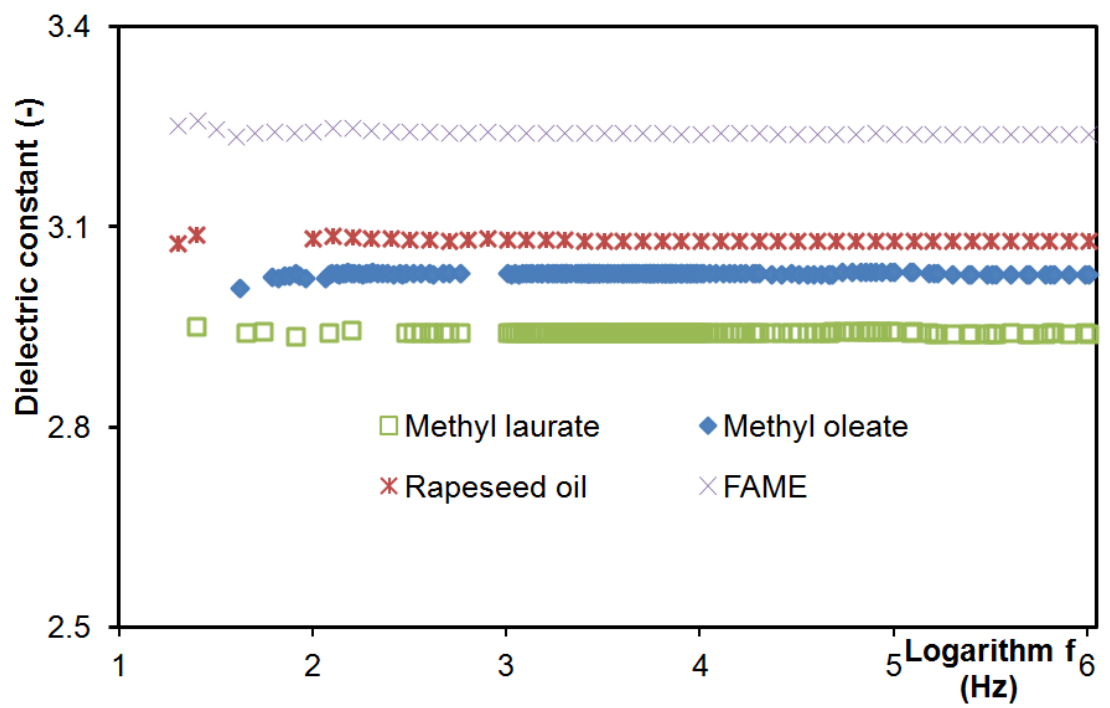

Figure 7: Frequency dependence of the dielectric constant for methyl oleate, methyl laurate, FAME and rapeseed oil.

tained are shown in Fig. 6, depending on a thousand times the inverse temperature.

\section{$2.2 \quad$ Dielectric properties}

For a study of dielectric properties, samples of FAME and rapeseed oil methyl ester were selected for a comparison with the two fatty acids found in rapeseed oil. Measurements were performed using the Agilent 4980 LCR meter and the Agilent 16452A electrode system for liquid samples. The highest relative permittivity value was 3.24 for FAME, and the lowest methyl value was for laurate 2.94 (Fig. 7).

Fig. 8 shows the dependence of relative permittivity on logarithmic frequency at various temperatures. The temperature was set using the Agilent16452A electrode system immersed in a Medingen KT-20 cryostat.

Size of variable loss numbers decreases negligibly with rapeseed oil and FAME. Value loss figures for a sample of methyl laurate and oleate decreased with increasing frequency and growing with temperature. The dependence of loss number of the logarithm frequency (Fig. 9) for a sample of methyl oleate is shown at different temperatures of the sample.

\subsection{Activation energy oils}

The external electric field in insulating liquids may be caused by ions, but the state can also occur when the ion captures the molecule, forming a single unit. The temperature effect can can cause the separation of ions 


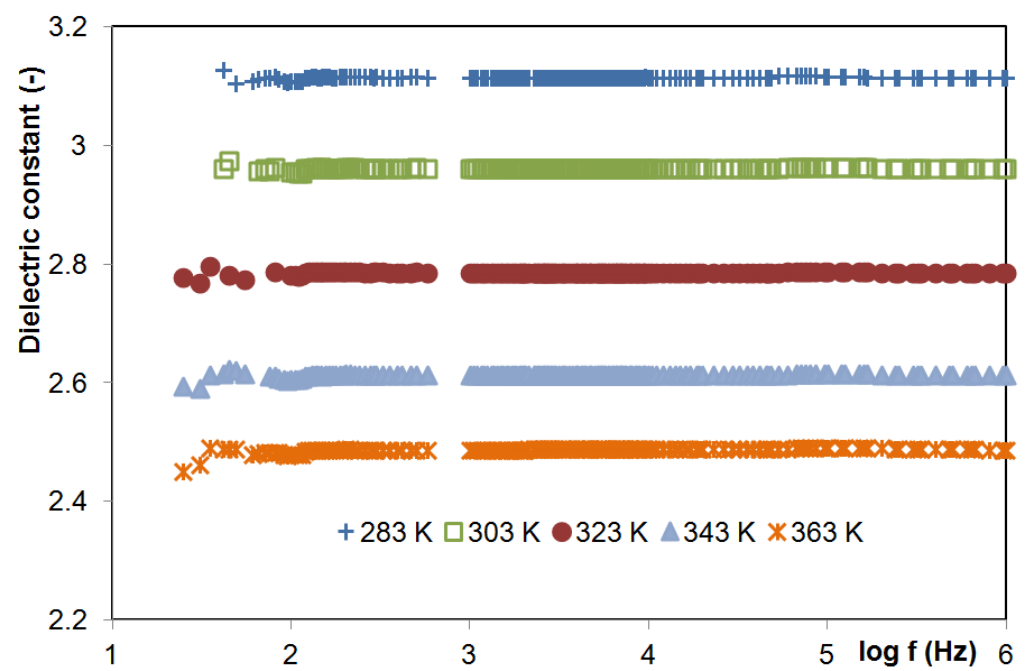

Figure 8: Frequency dependence of the dielectric constant for methyl oleate.

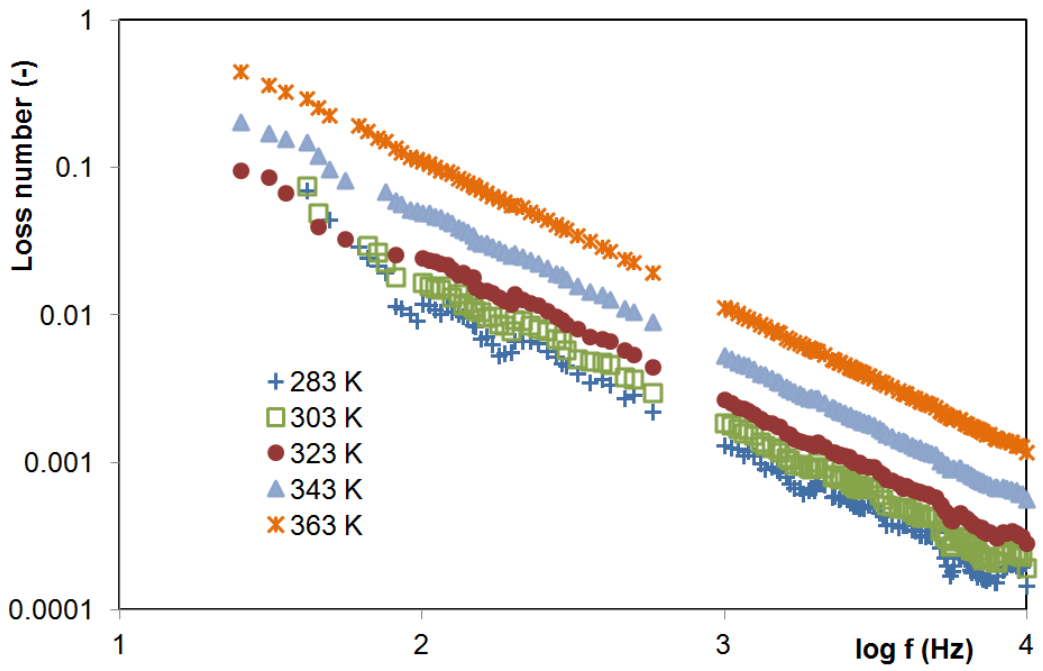

Figure 9: Frequency dependence of the loss number for methyl oleate.

and molecules add energy to overcome any potential barriers to activation energy $E_{A}$. In order to calculate the activation energy, we can use the temperature dependence of ionic conductivity according to the equation:

$$
\sigma=\sigma_{0} e^{-\frac{E_{A}}{k T}} .
$$

The highest activation energy value of $30.3 \mathrm{MJ} \mathrm{kmol}^{-1}$ was calculated for MIDEL 7131 oil, and the lowest value, $14.8 \mathrm{MJ} \mathrm{kmol}^{-1}$, was calculated for FAME. The second column compares the activation energy of the methyl esters of three acids found in rapeseed and other oils. Rapeseed oil with methyl oleate occurs in approximately $60 \%$ of the composition, and its activation energy was determined as $22.8 \mathrm{MJ} \mathrm{kmol}^{-1}$. The activation energy of rapeseed oil was $26.3 \mathrm{MJ} \mathrm{kmol}^{-1}$. The difference is a result of the ratio of the contents of different fatty acids in natural oils.

\section{Conclusion}

Fig. 10 shows the high conductivity values of rapeseed oil. The highest conductivity of $15 \mathrm{nS} \mathrm{m}^{-1}$ at frequency $1 \mathrm{MHz}$ is shown in rapeseed oil. The conductivity values of the other samples are given for a frequency of $10 \mathrm{kHz}$. FAME had the second highest conductance of $4 \mathrm{nS} \mathrm{m}^{-1}$. Methyl esters had the lowest conductivity: methyl laurate $0.087 \mathrm{nS} \mathrm{m}^{-1}$ and methyl oleate $0.097 \mathrm{nS} \mathrm{m}^{-1}$. The conductivity values for methyl esters were useless at frequencies above $30 \mathrm{kHz}$, because the values are close to the resolution threshold of the Agilent $4980 \mathrm{LCR}$ meter, that were loss number lower than 0.00001 (-). 


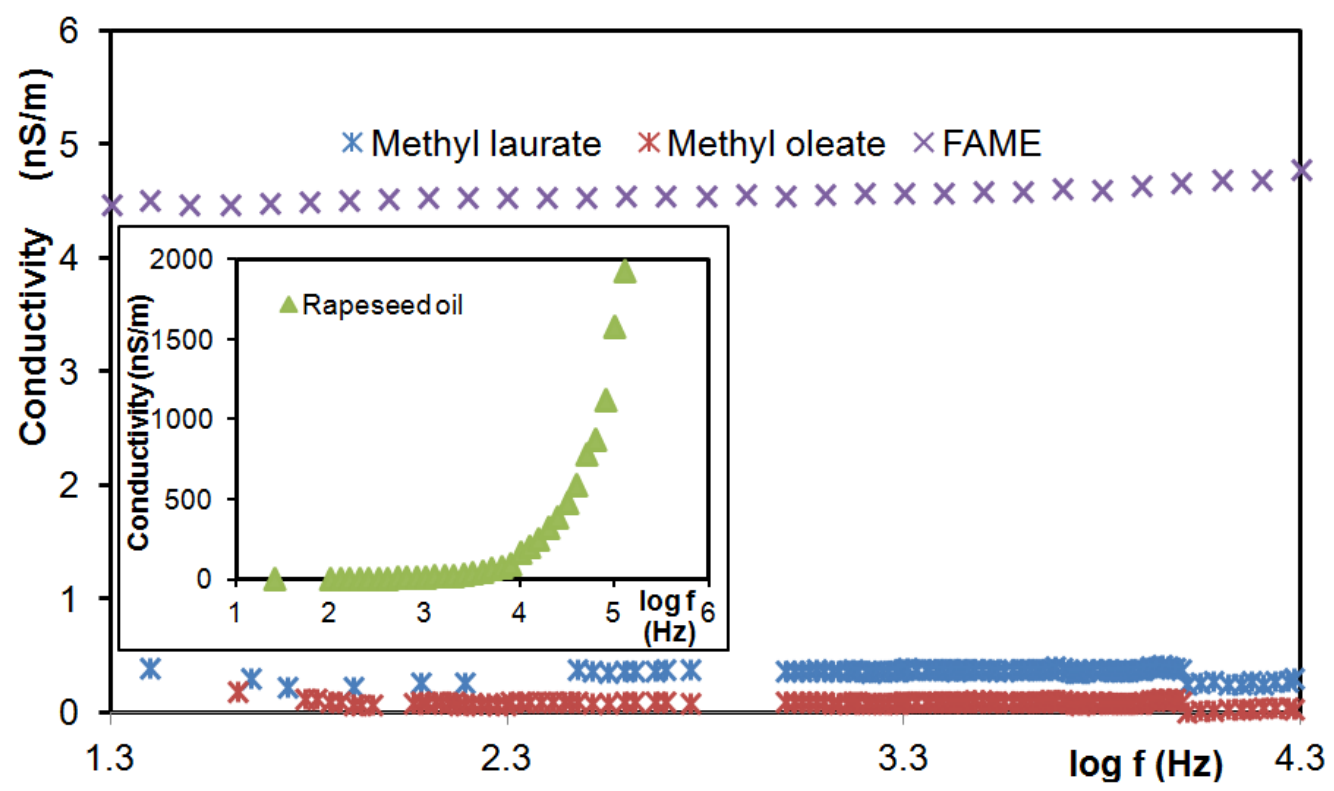

Figure 10: Logarithmic frequency dependence of conductivity for methyl esters, FAME and rapeseed oil.

\begin{tabular}{cc}
\hline Oil & Activation energy \\
\hline Midel 7131 & $30.3 \mathrm{MJ} \mathrm{kmol}^{-1}$ \\
\hline Rapeseed oil & $26.3 \mathrm{MJ} \mathrm{kmol}^{-1}$ \\
\hline Luko Oil Silik M 350 & $14.6 \mathrm{MJ} \mathrm{kmol}^{-1}$ \\
\hline Fame & $14.8 \mathrm{MJ} \mathrm{kmol}^{-1}$ \\
\hline Renolin Eltec T & $24.1 \mathrm{MJ} \mathrm{kmol}^{-1}$ \\
\hline
\end{tabular}

Table 2: Calculated parameters the activation energy of different types of oils.

\begin{tabular}{cc}
\hline Acid & Activation energy \\
\hline Methyl laurate & $30.2 \mathrm{MJ} \mathrm{kmol}^{-1}$ \\
\hline Methyl oleate & $22.8 \mathrm{MJ} \mathrm{kmol}^{-1}$ \\
\hline Methyl stearate & $8.7 \mathrm{MJ} \mathrm{kmol}^{-1}$ \\
\hline
\end{tabular}

Table 3: Calculated parameters the activation energy of fatty acids.

\section{Acknowledgements}

This research has been supported by the Internal Grant Agency of the Brno University of Technology within the framework of research project BD18102FEKT-S-11-11 on "Diagnostics of Material Defects", and by the Grant Agency of the Czech Republic within the framework of research project GD 102/09/H074 "Diagnostics of material defects using the latest defectoscopic methods".

\section{References}

[1] Agilent Technologies. Agilent 16452A Liquid Test Fixture: Operation and Service Manual. http://cp.literature.agilent.com/ litweb/pdf/16452-90000.pdf, 2000, [2011-05$22]$.

[2] Laboratoře UETE. Měř́ci př́stroje. http://laboratore.uete.feec.vutbr.cz/ ?id=merici-pristroje\&str=1\&device=4, 2011, [2011-04-26].

[3] C. P. McShane. Vegetable-oil-based dielectric coolants. Industry Applications Magazine 8: 3441, 2002.

[4] V. Mentlík. Dielektrické prvky a systémy. BEN technická literatura, Praha, 2006.

[5] M. Spohner. Diagnostika perspektivních elektroizolačních kapalin. Vysoké učení technické v Brně, Fakulta elektrotechniky a komunikačních technologií, 2011.

[6] P. Thomas, S. Sridhar, K. R. Krishnaswamy. Synthesis and evaluation of oleic acid esters as dielectric liquids. In International Symposium on Electrical Insulation, Montreal, Canada, 1996, pp. 565-568.

[7] Comparison of dietery fats. http://www . canolainfo.org/quadrant/media/downloads/ pdfs/ditfatpadFINAL.pdf, [2012-02-28] 